\title{
Application of Information Technology in Land field
}

\author{
Shuangying Jia \\ Xijing University, School of Electronic Information Engineering, Xi'an China, 710123 \\ 925297483@qq.com
}

\begin{abstract}
Keywords: Remote sensing; Geographical information; Global positioning system; Land information technology; Space technology
\end{abstract}

\begin{abstract}
Study and application of information technology in land field continues to deepen and cover wider range. After concluding the application of space information technology, including RS, GIS and GPS, in land field, this paper predicts the future direction of application of space technology in land field.
\end{abstract}

\section{Introduction}

As an information management technology, land information technology focuses on how to use remote sensing, geographical information system and global positioning system and other surface data collection technology to study the acquisition, analysis, treatment, storage and expression of all sorts of information in land resource management and provide advanced information technology for the macro-control and decision-making of land management[1]. With the core of space treatment technology, land information technology is the integration and collective name of geographical information system (GIS), geographical positioning system (GPS), remote sensing (RS) and other advanced technology in computer technology and normal methods of measurement and survey[2]. As information technology further develops, space information technologies like remote sensing (RS), geographical information science (GIS) and global positioning system (GPS) are also more widely applied in land field. Information technology, especially space information technology, has become the major tool of all land fields, thereby increasing the informatization level of land management.

\section{Development of RS and Its Application in Land Field}

As a tool of information collection, remote-sensing technology has been widely and deeply applied in all fields due to its characteristics of real-time, swiftness, wide coverage, multi-spectrum, periodicity, etc. As electrical technology constantly develops and improves, data acquisition capacity of satellite remote sensing is also advancing. At present, the satellite remote-sensing can acquire data below the level of meter, fully meeting the demand of small and medium-scale mapping. In China, there has been a three-multi (multi-platform, multi-sensor and multi-angle) and three-high (high space resolution, high spectral resolution and high temporal resolution) space-earth observation system and national remote-sensing satellite data acquisition and service system. The computer treatment of remote-sensing video data is more automatic and intelligent. The mechanism and quantification of remote-sensing conversely displays the automation and real time process of technology[3]. In land field, photographic survey and remote-sensing provides huge amounts of information of land information management system, and is regarded as an important tool of collect, update and modify the compiling data of small and medium scale existing land use map. It is widely applied in realms like land management, land coverage classification and supervision.

Land Resource Management. As an important tool of acquire data resource, remote-sensing is a major data source in land resource management. From 1980 to 1984, the first land use survey mapping in China applied Landset MSS remote-sensing technology with resolution ratio of $79 \mathrm{~m}$. In the detailed survey carried out from May in 1984 to May in 1995, highly precise remote-sensing data source was applied. In developed east China, aero photography data was used while TM data with resolution ratio of 30m was used in west China. Since 1999, land and resources survey applied 
remote sensing data with high resolution ratio for the first time. SPORTS satellite multispectral data with resolution ratio of $10 \mathrm{~m}$ and PAN of 2.5 were major data source. The application of remote-sensing provides the first-hand data for the survey on present land using and for the reasonable use and decision-making management of China's land resources. How to manage the massive remote-sensing data is a focus of study. Zhao et al made discussion on the treatment of remote-sensing video data and the establishment of database based on the land using factor classification of remote-sensing characteristics and property sheet structure[4].

Land Using and the Capture and Classification of Coverage Information. Remote-sensing video land coverage classification means that the image elements of remote-sensing video are classified to land coverage via some rules or algorithm based on their spectral brightness, space structural features and other information in different wave brand[5]. Obtaining remote-sensing video data is only the first step of applying remote-sensing in land use. Further study is based the useful image captured through classifying remote-sensing video. At present, methods of land coverage classification by remote-sensing at home and abroad are mainly visual interpretation, image classification based on statistical analysis (supervised classification and non-supervision), multivariate data fusion, expert system and spectrum analysis, etc[6].

On the basis of statistical analysis, there are supervision classification and non-supervision classification. The major statistical methods applied by non-supervision classification are mainly dynamic clustering, fuzzy clustering, system clustering and splitting[7]. Dynamic clustering refers to heuristic method, K-means algorithm, ISODATA and other methods based on proximity principle. The disadvantage of non-supervision classification is that the initialization conditions of classification, optimal classification centers and number cannot be determined[8]. Supervision classification first chooses characteristic variables according to an extracted sample; then it classifies all image elements through discriminate function. Supervision classification methods include maximal likelihood method, minimum distance method, Fischer linear discriminant classification, fuzzy classification, etc. Compared with non-supervision classification, supervision classification is more widely and better applied in remote-sensing classification of land coverage.

Multi-source image fusion refers to the process in which various sensor images (data source) or image at different wave brand or different resolution ratio integrate to generate a group of new image. They have more characteristics and knowledge, and higher application efficiency of data, thereby increasing the clarity and identifiability and improving the precision of classification $[9,10]$.

Classification method based on spectrum analysis is one based on the reflected light of landmark object. Song et al[10] used Fourier transformation to conduct preliminary research on the classification of land coverage remote-sensing images. Moller-Jenson[12] proposed a method to use the image spectrum characteristics of NOAAAVHRR to build up water extraction model. Normalized difference index is also a method of information extraction based on spectral characteristic, including NDVI, NDWI, MNDWI, NDBI, NDMI, NDSI, etc.

With combination of geoscience knowledge, expert knowledge system and other sciences like GIS, the precision of land use and coverage classification can be greatly improved compared with supervision classification[13,14,15].

Research Method on Remote-sensing Supervision of Land Use Change. Changes in land use reveal human or natural influence on land type. Land use supervision based on remote-sensing first obtains remote-sensing images at early or late stages and then conducts geometric correction, registration and integration. Next, overlapped analysis on the changes in features is made to complete land use change mapping. Compared with original manual research method, those based on remote-sensing can greatly improve work efficiency and duty cycle. In China, supervision on land use change information has undergone three major stages: manual study, aerial photography assisted supervision and dynamic supervision dominated by remote-sensing data. Remote-sensing has been widely applied in land use supervision studies, with sophisticated process generated[16,17,18,19,20]. Combination of GIS and remote-sensing technology is an effective way to realize the monitoring application system of land use and coverage[18,19,20]. First, the precision of classification can be improved by using remote-sensing information to assist the interpretation of 
land use type supported by GIS fundamental database. Second, the present advantage of GIS can be maintained by using the latest information on land use extracted by remote-sensing data extraction to complement and update GIS database. Third, functions like GIS space overlapping analyzing can be used to conduct dynamic analysis at various stages to supervise the change in land use and assist in land use decision-making[19]. The present stage features key technology study and application. Like Shao et al, Taking the land use dynamic supervision system study in a demonstrating zone to illustrate the key technology and procedures of its change polygons' extracting sub-system[20].

Analysis on the application of remote-sensing in land field. Remote-sensing science has been widely applied in land field, promoting the application and study of land field in China. At present, further study should be made in the following aspects:

(1) Storage and inquiry of massive remote-data. Today, the storage of remote-sensing video data is mainly in the form of document or large-scale database. The current document form and huge database falls short of the demand of the constant update of massive remote-sensing data.

(2) Data mining methods. Remote-sensing data provides abundant data resource. At present, application of such a huge resource is mainly in the common application field. In land field, application is mainly in the dynamic supervision of land, land management, land coverage change study, etc. However, how to make best use of data resource via in-depth mining of remote-sensing data is an important direction in the future.

(3) Interdisciplinary application. Since remote-sensing is a data providing method, it should be combined with other disciplines to give rise to the information in land fields.

\section{Development of GIS and Its Application in Land Field}

After decades of development, GIS technology has become quite sophisticated, providing great space analyzing and processing ability and giving rise to numerous commercial GIS systems applied in all fields..As Internet technology and three-dimensional virtual technology continue to advance,. its research in application field will be certainly influenced and promoted.

Land Management. In China, total area is vast but per capita area is small. Since cadastral changes very frequently, land information is complicated and massive. Therefore, improving land management quality, efficiency and level is the foundation of reasonably using the limited land resources. In China, information-based and digital land management further improves. In all land departments, land management information systems are successively established, offering accurate, fast and all-round land information inquiry service and technology support for the management and decision-making of land resources. GIS plays a critical role in land management information system establishment. In essence, this system is designed to meet the demand of modern land resource management. Based on the widely applied computer network, information engineer, database management and space modeling and a series of advanced modern science and technology, engineers used GIS data processing and analyzing methods to develop a space management information system, thereby collecting, processing, storing, managing, questing, analyzing, applying, maintaining and updating all space and non-space information and characteristics[21]. Since the 1990s, GIS has become increasingly sophisticated in land management application. Advanced application system has formed.

Research on Land Use Change and Dynamic Supervision. Land use/land coverage is one of the core issues in the field of global environmental change research[22]. Researches on land use change, especially on land space change, rely on GIS space analyzing method[23]. First, at data processing stage, GIS system combines vector data, attribute data as well as remote-sensing data into the system, concerning facilities like data conversion, editing, database operating, etc. In the process of analysis, the combination of space analysis of GIS, space statistical function and related analysis model conducts analytical prediction on the change in land use. At last, the graphical image of GIS shows function display and simulated analysis results. The common thinking of domestic land use change prediction research is: under the support of RS or GIS technology, aiming at all sort of data which can be collected in a certain area and time period, based on land use change, relevant model is applied to predict the trend of land use in this area, thereby realizing the historical process 
simulation and trend prediction of the land use change in this area[24]. The major applications of RS and GIS are: analysis on land use change and spatial pattern simulation based on statistical analysis technology, land resources number change model, land use degree change model and transition probability matrix[25,26,27,28,29]; simulation on land use change and spatial pattern based on the random model transformed by Markov[30]; investigation on driving forces of land use change by using mathematical methods[31,32]; supervision system on land use change[33], etc.

Application of GIS in Land Use Planning. GIS has become a power tool in the overall process of land planning. At the preparing and analyzing stage, land use space information system is established based on GIS to provide detailed information for land use planning; at the middle stage of design, the powerful space analyzing ability can help make decision, such as land adaptability evaluation, land planning equilibrium analysis, planning technology indicator analysis, etc. For instance, remote-sensing data and the powerful managing and analyzing ability of GIS on geographical space information can help accurately account the scale of farm land and environmental volume, conduct all technological, economic and ecological indicators analysis related to land use planning design and complete the calculation of indicators in land use planning of land leveling, matrix improvement construction volume and adaptability to surrounding environment, etc, thereby effectively determining the application direction of all fields and helping make reasonable choices in the land use planning.

\section{Development of GPS and Its Application in Land Field}

GPS is all-weather, highly accurate, automatic and highly efficient. It is mainly used in land positioning in the course of measurement. At present, the space three-angle measurement assisted by GPS can be as accurate as centimeter, fully meeting the mapping demand of large and medium scale. It has been widely applied in land survey and mapping[34]. The development and application of current GPS technology is mainly in the following aspects:

(1)Research and application of new measuring methods, such as real-time kinematic(RTK)[35,36]. RTK develops based on GPS. It can offer real time three-dimensional positioning coordinate of mobile station in a given coordinate system. In a certain distance range, its precision can be centimeter[35].

(2) Facilitate GPS precision study[37,38].

(3) Component, working process of statistical data collecting system based on GPS [39,40].

(4) Application of GPS-PDA in data collecting[41,42].

(5) $3 \mathrm{~S}$ Integration. It refers to use RS to conduct preliminary remote-sensing image data interpretation and information mining, to use GPS to conduct measurement and survey on outdoor land and to use GIS to manage and analyze data[43,44]. 3S integrated technology can make land use information more reliable and precise.

\section{The Future Development of Land Information Technology}

Land information technology has been thoroughly applied to various fields. Its future development is mainly reflected in the following aspects:

(1) A variety of information technology integration and comprehensive application. Single technology normally cannot complete a task very well. Comprehensive a variety of information technology, especially the $3 \mathrm{~S}$ technology integration in the application, is the key to solve land problems in the future.

(2) The use of information technology for deep mining of spatial information. Currently, land use of information technology is mainly in daily land management and monitoring. In-depth information of land coverage and land use hasn't been explored. So it is needed to use land information technology to establish land spatial information mining system.

(3) Following the development of technology closely to expand the application of new technology in the land. As information technology constantly evolving, land information technology will improve the level of land use research and service by using new technology. For example, 
expanding the three-dimensional GIS technology to simulate and analyze land use, using web GIS technology for land information sharing, etc.

\section{References}

[1] R.Q. Zhang: L and Resources and Environment, (2001) No.4, p.13.(In Chinese)

[2] Y. Li and G.X. Zhao: Areal Research and Development, Vol. 25 (2006) No.6, p.94. (In Chinese)

[3] C.R. Yang and H.S. Zhang: Sci-Tech Information Development and Economy, Vol. 18 (2008) No.1, p. 132. (In Chinese)

[4] H.Y. Zhao and L.J. Bu: Urban Geotechnical Investigation and Surveying, (2008) No.6, p.82. (In Chinese)

[5] J. Wang: Remote Sensing Monitoring and Evaluation of Land Resources (Science Press, China 2006). (In Chinese)

[6] X.B. Sun, W. Fan and P. Yan: Chinese Agricultural Science Bulletin, Vol. 23 (2007) No.9, p.607. (In Chinese)

[7] W.L. Peng: Introduction to Remote Sensing (Higher Education Press, China 2002). (In Chinese)

[8] C.X. Zhao and L.X. Qian: Journal of Henan University (Natural Science), Vol. 34 (2004) No.3, p.90. (In Chinese)

[9] L.Y. Liu: Journal of Soil and Water Conservation, Vol. 23 (2009) No.1, p.222. (In Chinese)

[10] Y. Song and Y.C. Wan: Remote Sensing Information, (2007) No.1, p.3. (In Chinese)

[11]Z.J. Liu, C.Y. Wang and H. Yan: Journal of Image and Graphics, Vol. 8 (2003) No.2, p.151. (In Chinese)

[12]L. Moller-Jensen: PEandRS, Vol. 56 No.6, p.899.

[13]P. Guo, Y.L. Sun and H.B. Liu: Journal of Southwest Agricultural University, Vol. 25 (2003) No.3, p.279. (In Chinese)

[14]N. Xu, X.D. Guo and S.F. Tian: Acta Ecologica Sinica, Vol. 28 (2008) No.11, p.5410. (In Chinese)

[15] J. Yang and K. Qin: Journal of Henan Polytechnic University, Vol. 27 (2008) No.6, p.666. (In Chinese)

[16] S.H. Jin: Geomatics and Spatial Information Technology, Vol. 29 (2006) No.1, p.98. (In Chinese)

[17]Z.H. Dai, T. Tashfulati and Y.G. Ma: Desert and Oasis Meteorology, Vol. 1 (2007) No.6, p.17. (In Chinese)

[18] J.T. Liang: Acta Geologica Sichuan, Vol. 29 (2009) No.1, p.111. (In Chinese)

[19]H.L. Zhang, B. Hu and J.F. Yi: Image Technology, (2004) No.2, p.43. (In Chinese)

[20] Y.S. Shao, S.M. Zhang and L.Y. Zhang: Computer Engineering and Applications, Vol. 45 (2009) No.9, p.161. (In Chinese)

[21] Y. Zhou and Y. Nie: Land Information System (Chemical Industry Press, China 2005). (In Chinese)

[22] B.L. Turner and W.B. Meyer: International Social Science Journal, (1991). 
[23]H.Y. Zhu, S.J. He and M. Zhang: Progress in Geography, Vol. 20 (2001) No.2, p.104. (In Chinese)

[24] J.Q. Zhang and S.Q. Wei: Journal of Anqing Teachers College, Vol. 10 (2004) No.2, p.96. (In Chinese)

[25] Y.L. Li and J.Z. Tan: Science of Surveying and Mapping, Vol. 34 (2009) No.2, p.216. (In Chinese)

[26]X. Song, D.X. Shi and X. Li: Journal of Henan Agricultural University, Vol. 42 (2008) No.4, p.454. (In Chinese)

[27] Q. Zeng, G.M. Yu and S. Yang: Journal of Huazhong Agricultural University, Vol. 27 (2008) No.2, p.223. (In Chinese)

[28] M.Z. Bai and Q.L. Yue: Journal of East China Institute of Technology, Vol. 30 (2007) No.4, p.345. (In Chinese)

[29] Y.F. Zheng, Y.M. Nie and Z.Y. Li: Journal of Anhui Agri. Sci., Vol. 36 (2008) No.24, p.10587. (In Chinese)

[30] Y.L. Wang and Z.F. Li: Journal of Anhui Agri. Sci., Vol. 35 (2007) No.20, p.6226. (In Chinese)

[31]C.Y. Zheng and H.K. Hu: Hubei Agricultural Sciences, Vol. 47 (2008) No.11, p.1350. (In Chinese)

[32]X.J. Qi and E.D. Wang: Geology and Resources, Vol. 17 (2008) No.4, p.318. (In Chinese)

[33] Y.F. Liu: Gold Science and Technology, Vol. 17 (2009) No.2, p.68. (In Chinese)

[34] L.J. Shi: Journal of Xingtai Polytechnic College, Vol. 26 (2009) No.1, p.102. (In Chinese)

[35] Q.P. Ren and S.L. Zhao: Journal of Hebei Agricultural Sciences, Vol. 12 (2008) No.9, p.77. (In Chinese)

[36]Q. Zhang, S.Y. Hu and Y.Y. Shi: Geomatics and Spatial Information Technology, Vol. 31 (2008) No.2, p.20. (In Chinese)

[37] S.Y. Xing: Friend of Science Amateurs, (2008) No.8, p.110. (In Chinese)

[38] X.M. Chen and Y. Liu: Science and Technology Information, (2007) No.30. (In Chinese)

[39] S.X. Xia: Oil-Gas Field Surface Engineering, Vol. 27 (2008) No.3, p.20. (In Chinese)

[40] B. Wu: Manager' Journal, (2008) No.15. (In Chinese)

[41] C.P. Ti, X.S. Jiang and J.C. Liu: Remote Sensing Information, (2008) No.6, p.58. (In Chinese)

[42] B.H. Feng and J.D. Shao: Geotechnical Investigation and Surveying, (2008) No.3, p.71. (In Chinese)

[43] X.D. Li, W.N. Yang and L. Ma: Science of Surveying and Mapping, Vol. 33 (2008) No.6, p.209. (In Chinese)

[44]Z.Z. Zheng, D.M. Fan and W.N. Yang: Journal of Southwest Jiaotong University, Vol. 42 (2007) No.4, p.409. (In Chinese) 